\title{
The poor man's cell block
}

\author{
Frederick Mayall, ${ }^{1}$ Ann Darlington ${ }^{2}$
}

1Department of Histopathology, Musgrove Park Hospital, Taunton, UK

${ }^{2}$ Department of Pathology, Waikato Hospital, Hamilton, New Zealand

\section{Correspondence to} Dr F G Mayall, Musgrove Park Hospital, Taunton TA1 5DA, UK; mayallf@wave.co.nz

Accepted 12 May 2010 Published Online First 29 July 2010

\section{ABSTRACT}

The authors describe a simple method for making formalin or isopropyl alcohol vapour fixed cell blocks from fine needle aspiration cytology specimens that we refer to as 'The Poor Man's Cell Block.'

The utility of fine needle aspiration cytology can be enhanced by the collection of cell blocks for immunohistochemistry and other molecular studies. We describe a method for making vapour fixed cell blocks that we have developed over the last 10 years. This technique, which we refer to as 'The Poor Man's Cell Block,' requires no equipment or reagents that are not available in an outpatient department or a radiology department. It has developed from a method that we first described in 2003. ${ }^{1}$ The material is expelled from the fine needle aspiration needle to form a blob on the inside of the inverted lid of a universal container (figure 1) Sometimes the specimen is expelled as several blobs. These can be shepherded back into a single larger blob by an 'air-football' technique using puffs of air from the now empty needle and syringe. The lid is left inverted while a ball of tissue paper is pushed into the bottom of the universal container. A small amount of formalin, about $2 \mathrm{ml}$, is added to the container and soaks into the tissue paper. Alternatively one can push two isopropyl alcohol phlebotomy swabs into the bottom of the container. The container is screwed on to the inverted lid. The container is then left in the inverted position for at least $6 \mathrm{~h}$ at room temperature. By this time, the specimen has been fixed by the vapour and has become solid. It can be prised off the lid of the container with the edge of a scalpel and processed as if it were a biopsy. The specimen is best removed by first flooding the lid with a small amount of formalin so as to gently break the 'limpet' suction between the specimen and the lid. It is important not to let the specimen dry out once it has been removed from the lid, as this makes the specimen hard to section and causes cellular artefact. It should be cassetted and immersed in formalin as soon as possible. The use of isopropyl alcohol swabs is arguably preferable to the use of formalin, as handling formalin is considered to be more hazardous, and isopropyl alcohol vapour appears to fix the cell block more rapidly than formalin vapour. In addition, formalin vapour fixation may give rise to prominent formalin pigment. However, alcohol fixation of any type of cytology specimen should not be used without regard for the changes in immunohistochemical methods that are then required. Formalin-fixed control sections are no longer appropriate, and different antigen retrieval methods may be needed. For this reason, formalin vapour fixation is probably the more practical method. The cell block method described above gives a higher density of cells in the sections than gel block methods. 

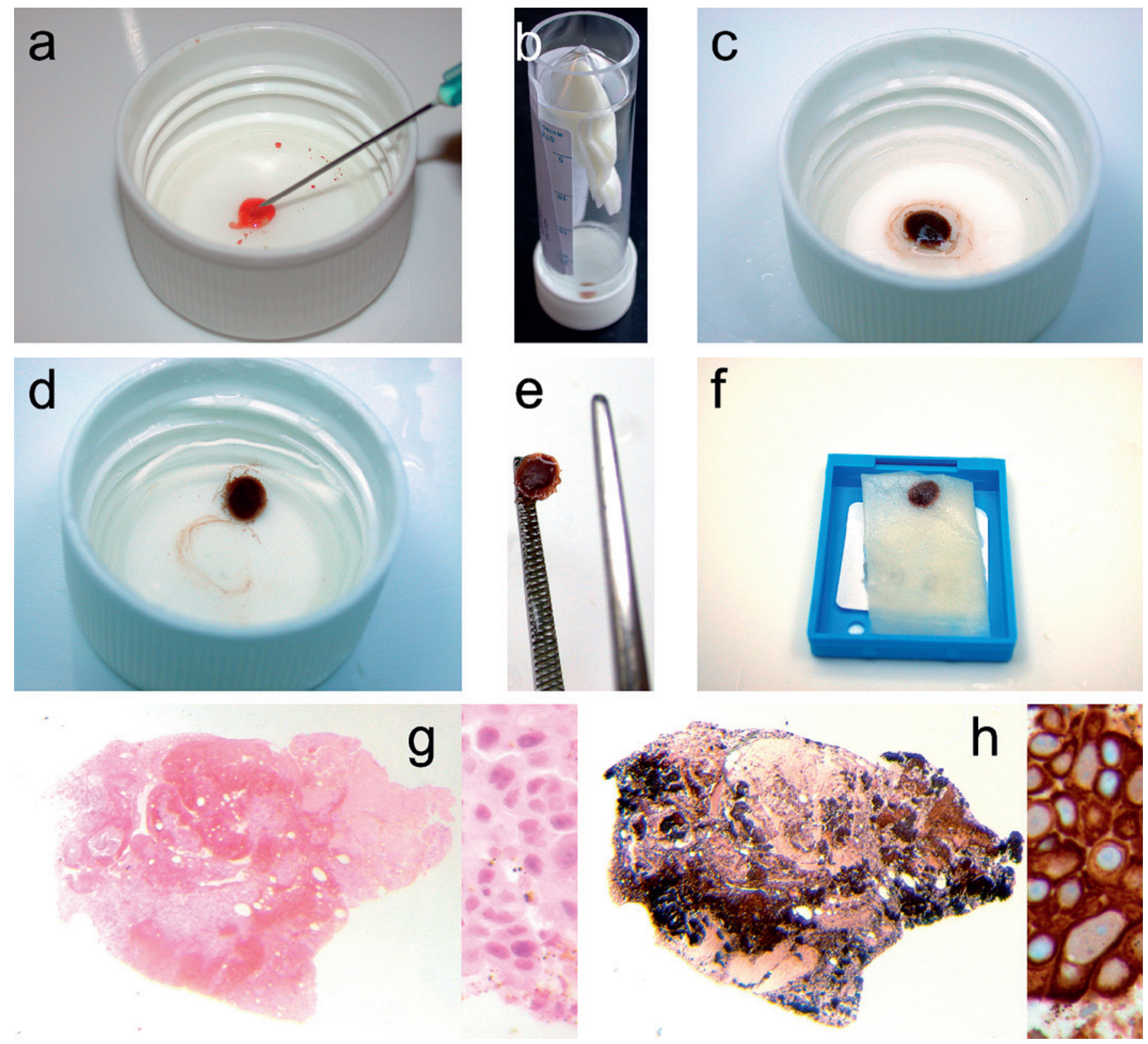

Figure 1 Images demonstrating the main steps in the preparation of a vapour fixed cell block. (A) The fine needle aspiration material is expelled to form a blob. (B) The universal container is left inverted for at least $6 \mathrm{~h}$ to allow the material to vapour fix. (C) The material is now solid. (D) The lid is flooded with a small amount of formalin so as to help gently break the 'limpet' suction. (E) The solid cell block can be picked up, being careful not to let it dry out. (F) The specimen should be wrapped in tissue paper for processing. (G) H\&E section showing the low-power appearances and high-power detail (metastatic breast carcinoma). (H) Low-power appearances and high-power detail of a cytokeratin 7 immunostain showing that the cells are densely distributed in the cell block.

\section{Take-home messages}

- Vapour-fixed fine needle aspiration cell blocks are simple and cheap to make.

- No special reagents or equipment are required.

- The sections show dense cellularity.

\section{Competing interests None.}

Provenance and peer review Not commissioned; externally peer reviewed.

\section{REFERENCE}

1. Mayall F, Darlington A, Harrison B. Fine needle aspiration cytology in the diagnosis of uncommon types of lymphoma. J Clin Pathol 2003;56:728-30. 